\title{
Requisitos de projeto para o desenvolvimento de jogos digitais utilizando a interface natural orientados aos idosos
}

\author{
Design requirements for the development of digital games using the \\ natural user interface oriented to the elderly
}

PILLON, Carolina Bravo

Universidade Federal do Rio Grande do Sul - UFRGS I carolinabpillon@gmail.com

SILVA, Régio Pierre da

Universidade Federal do Rio Grande do Sul - UFRGS I regio@ufrgs.br

ALMEIDA, Carla Skilhan de

Universidade Federal do Rio Grande do Sul - UFRGS I carlaskilhan@gmail.com

\begin{abstract}
Resumo
O aumento da população de idosos implica em ações específicas para atender as suas necessidades e exigências. Nesse sentido, essa pesquisa visa oferecer suporte teórico e metodológico para o desenvolvimento de jogos digitais que atendam às necessidades dos idosos. Objetivo: estabelecer um conjunto de requisitos de projeto para apoiar o desenvolvimento de jogos digitais que utilizam a interface natural, a partir da perspectiva dos usuários idosos, a fim de contribuir para a melhora na qualidade de vida. Metodologia: trata-se de um estudo de caso realizado durante oito semanas com três idosos frequentadores do projeto de extensão do Centro de Estudos de Lazer e Atividade Física do Idoso (Celari) da Escola de Educação Física (ESEF) da Universidade Federal do Rio Grande do Sul (UFRGS). Resultados: por meio da aplicação do Desdobramento da Função Qualidade (QFD), foi obtido um conjunto de requisitos de projeto sistematizados de acordo com o grau de importância atribuído pelos usuários idosos. Conclusões: os resultados encontrados nessa pesquisa podem, eventualmente, orientar o desenvolvimento de um jogo digital utilizando a interface natural para os idosos.
\end{abstract}

Palavras-chave: Envelhecimento. Interface natural do usuário. Jogos digitais. Requisitos de projeto.

\section{Abstract}

The increase of the elderly population implies specific actions to meet their needs and preferences. In this context, this paper aims to offer theoretical and methodological support for the development of digital games that meet the needs of the elderly. Objective: establishing a set of design requirements to support the development of digital games using the natural user interface from the perspective of elderly users, in order to improve their life quality. Methodology: a case study performed during eight weeks with three aged people within the extension project of the Center of Studies of Leisure and Physical Activity for the Elderly (Celari) from the School of Physical Education (ESEF) at the Federal University of Rio Grande do Sul (UFRGS). Results: through the application of the Quality Function Deployment (QFD), a set of design requirements was structured according to the degree of importance assigned by the elderly users. Conclusion: the results found in this research may guide the development of digital games using the natural user interface for the elderly.

Keywords: Natural user interface. Digital games. Design requirements.Journal. Research. 


\section{INTRODUC̣ÃO}

O envelhecimento é um fenômeno observado tanto em países desenvolvidos quanto em países em desenvolvimento. Conforme Camarano e Kanso (2011), o envelhecimento humano é um processo irreversível, natural e individual, acompanhado por perdas progressivas de função e de papéis sociais. Já o envelhecimento demográfico consiste em um aumento da participação de pessoas idosas no total da população, somado a uma redução na taxa de fecundidade e ao aumento da expectativa de vida.

Segundo a OMS (2005), o aumento da expectativa de vida da população deve ser acompanhado de uma melhoria ou manutenção da saúde e qualidade de vida. A adoção de hábitos saudáveis, como a prática de atividade física, contribui para a independência e melhora da percepção da qualidade de vida dos idosos. A OMS (1994 apud OMS, 2005, p. 14) descreve o seguinte conceito de qualidade de vida:

[...] a percepção que o indivíduo tem de sua posição na vida dentro do contexto de sua cultura e do sistema de valores de onde vive, e em relação a seus objetivos, expectativas, padrões e preocupações. É um conceito muito amplo que incorpora de uma maneira complexa a saúde física de uma pessoa, seu estado psicológico, seu nível de dependência, suas relações sociais, suas crenças e sua relação com características proeminentes no ambiente.

Uma das alternativas para viabilizar a prática de atividades é através das novas tecnologias de intervenção baseadas nos jogos digitais. Esses dispositivos adotam a interface natural do usuário (em inglês, Natural User Interface - NUI) que permitem interagir com um computador da mesma maneira como se interage com o mundo físico através da utilização da voz, mãos e corpo. As interfaces naturais utilizam as habilidades cotidianas, como falar, escrever, gesticular, andar e pegar objetos, para criar formas naturais de interação (ROGERS; SHARP; PREECE, 2013).

Várias pesquisas sugerem a eficácia das tecnologias de intervenção baseadas nos jogos digitais em idosos. Wibelinger et al. (2013), por exemplo, demonstraram os efeitos de um treinamento utilizando os jogos comerciais, dos quais possuem uma interface natural, em relação às doenças musculoesqueléticas. Entretanto, é importante referir que as necessidades e preferências dos usuários idosos não são tratadas de forma adequada com esses jogos, conforme conclui os estudos de Marinelli e Rogers (2014) e McLaughlin et al. (2012). 
É necessário desenvolver produtos interativos que levem em consideração as limitações decorrentes do processo de envelhecimento que podem atingir as funções motoras, cognitivas e sensoriais. Portanto, o objetivo dessa pesquisa consiste em estabelecer um conjunto de requisitos de projeto para apoiar o desenvolvimento de jogos digitais que utilizam a interface natural, a partir da perspectiva dos usuários idosos, a fim de contribuir para a melhora na qualidade de vida.

\section{REVISÃO DE LITERATURA}

Nessa seção são abordados os principais conceitos sobre 0 envelhecimento, jogos digitais e interface natural do usuário.

\subsection{Envelhecimento}

De acordo com o IESS (2013), observou-se uma alteração na composição da pirâmide populacional, no qual o grupo de pessoas mais velhas tornou-se proporcionalmente maior em relação ao restante da população. O estreitamento na base da pirâmide populacional indica uma redução no contingente de crianças e adolescentes com idade entre 0 e 19 anos. Em contrapartida, o alargamento no topo da pirâmide demonstra que ocorreu um considerável incremento da população idosa (IBGE, 2010).

A proporção de crianças e adolescentes com menos de 15 anos na população mundial diminuiu de 38\% em 1965 para 26\% em 2013, e vai continuar diminuindo nas próximas décadas. A proporção de adultos ativos com idades entre 15 e 59 anos aumentou de 54\% para 62\%, porém deverá diminuir gradualmente no decorrer dos anos. A população idosa com 60 anos ou mais tem mostrado um aumento persistente na proporção da população mundial (UNITED NATIONS, 2013).

No Brasil, o percentual da população com mais de 60 anos de idade passou de 9,1\% em 1999 para 11,3\% em 2009. A população com mais de 65 anos de idade passou de 6,2\% em 1999 para 7,8\% em 2009.

O aumento da expectativa de vida ao nascer se deve, entre outros aspectos, aos avanços na medicina e na saúde pública, às melhores condições de alimentação, ao aumento da renda e ao controle de vetores causadores de doenças infecciosas. Como resultado dessas melhorias, houve uma redução nas taxas de mortalidade não somente na infância como também nas idades mais avançadas e um crescimento do grupo populacional idoso (IESS, 2013). 
A expectativa de vida ao nascer irá aumentar nas próximas décadas em todas as regiões do mundo. Entre os anos de 2010 a 2015, a expectativa de vida ao nascer foi de 78 anos nos países desenvolvidos e de 68 anos nos países em desenvolvimento. A diferença da expectativa de vida ao nascer nos países tende a continuar diminuindo nas próximas décadas. Entre os anos de 2045 a 2050, projeta-se que a expectativa de vida irá atingir 83 anos nos países desenvolvidos e 75 anos nos países em desenvolvimento (UNITED NATIONS, 2013).

Segundo o IBGE (2010), as projeções demográficas indicam que a expectativa de vida ao nascer no Brasil foi de 70,21 anos para os homens e de 77,60 anos para as mulheres em 2010. Esse índice deve atingir 78,0 para os homens e 84,4 anos para as mulheres em 2060 (IBGE, 2010).

Diante dos dados mencionados, convém notar que as alterações demográficas ocorridas nas últimas décadas provocaram um aumento da população senescente no Brasil e no mundo. Esse incremento requer um cuidado especial a fim de assegurar que as pessoas idosas possam viver com dignidade e segurança, por meio de ações que ampliem a sua autonomia e independência, assim como contribuam para um envelhecimento mais saudável (UNFPA, 2012).

\subsection{Jogos Digitais}

Novas tecnologias de intervenção baseadas nos jogos digitais vêm sendo exploradas, como os consoles de videogames comerciais Nintendo Wii ${ }^{\circledR}$, Microsoft Kinect ${ }^{\circledR}$ e PlayStation EyeToy ${ }^{\circledR}$. Considerando-se que esses sistemas utilizam a movimentação do corpo como dispositivos de interação, as interfaces dos jogos tornam-se mais naturais e intuitivas atraindo um público de jogadores idosos que não possuem familiaridade com os controles dos consoles de videogames.

Enquanto os sensores, como o $\operatorname{Kinect}^{\circledR}$, podem ser considerados dispositivos de entrada baseado em hardware, os jogos digitais são vistos como dispositivos de saída baseados em software. Schuytema (2008) descreve um jogo como uma atividade lúdica composta por uma série de ações e decisões, limitado por regras e pelo universo do jogo, que resultam em uma condição final. Salen e Zimmerman (2012) caracterizam um jogo como um sistema no qual os jogadores se envolvem em um conflito artificial, definido por regras, que implica um resultado quantificável.

Os jogos são conceituados de uma forma diferente por diferentes autores, assim como os gêneros dos jogos que, frequentemente, reúnem em si mais de um desses gêneros resultando em uma imprecisão de termos. 
Rogers (2012) descreve os gêneros e subgêneros de jogos, tais como: ação, tiro, aventura, construção e simulação, estratégia e simulação de veículos. Pode-se citar ainda, o gênero dos jogos sérios (em inglês, serious games) com aplicações em várias áreas como educação, política e também na área da saúde.

Um jogo sério, de acordo com Michael e Chen (2006), é um jogo em que a educação, em suas diversas formas, é o principal objetivo, mais do que entretenimento. A medicina moderna, tanto biológica quanto psicológica, começou a se interessar pelo videogame devido ao seu potencial de cura. Segundo os autores, estudos buscam demonstrar que videogames podem ajudar na recuperação dos pacientes, ajudar os médicos a se preparar para cirurgias delicadas, promover o bem-estar e ajudar os pacientes com problemas mentais.

Nesse sentido, alguns pesquisadores buscaram avaliar os efeitos de um treinamento utilizando as tecnologias de intervenção baseadas nos jogos digitais na saúde dos idosos em relação à vários aspectos, entre eles: cognitivos (MAILLOT; PERROT; HARTLEY, 2012), físicos (TREML et al., 2013) e psicológicos (WI; KANG; JANG, 2013). Na maioria das publicações levantadas, observou-se a aplicação dos jogos comerciais, dos quais apresentam uma dinâmica baseada nos movimentos do corpo, incluindo atividades relacionadas à dança, esporte, aventura e treinamento.

A partir da revisão de literatura, foi possível demonstrar que a utilização das tecnologias baseadas nos jogos digitais pode, eventualmente, promover a melhora da capacidade funcional dos idosos. Percebe-se, entretanto, que é preciso fomentar a realização de mais pesquisas com o propósito de gerar conhecimento para a área de Design em relação aos aspectos que devem ser levados em consideração na produção de um jogo digital orientado aos usuários idosos.

\subsection{Interface Natural do Usuário}

Para Wigdor e Wixon (2011), a interação natural é realizada por meio dos gestos em superfícies sensíveis ao toque (touchscreen) ou a partir dos gestos com movimentos no ar (air-based gestures). Segundo Rogers, Sharp e Preece (2013), a interação baseada nos gestos com movimentos no ar funciona através de um conjunto de sensores e microfones que capturam os dados referentes à movimentação e a fala do usuário. A informação é representada na tela por meio de um avatar que executa os mesmos movimentos do usuário como um espelho virtual. Os autores consideram que o feedback fornecido na tela, em resposta aos gestos no ar, torna-se extremamente eficaz quando o jogador se visualiza como avatar e aprende a jogar de maneira mais física. 
As informações apresentadas a seguir têm como referencial teórico o guia para desenvolvedores de aplicativos para o Kinect ${ }^{\circledR}$ elaborado pela Microsoft (2013). O referido guia utiliza uma estrutura baseada em prós e contras (em inglês, Do e Don't) com o propósito de orientar o desenvolvimento de aplicativos utilizando o Kinect ${ }^{\circledR}$ para o Windows. Na ausência da referência deve-se considerar que o texto foi fundamentado no guia sobre os princípios de design para a interface do Kinect ${ }^{\circledR}$.

A movimentação do corpo é utilizada como dispositivo de entrada na interface natural. Os gestos podem assumir várias formas, desde a simples tarefa de utilizar a mão para acessar um item na tela, até situações em que o usuário deve aprender os padrões de um movimento contínuo utilizando todo o corpo.

Os gestos podem ser classificados em inatos ou aprendidos. Os gestos inatos são àqueles que o usuário consegue executá-los intuitivamente com base no conhecimento sobre o mundo físico. Os principais exemplos de gestos inativos são: apontar, agarrar e pressionar. Os gestos aprendidos precisam ser ensinados e memorizados pelo usuário para interagir com o aplicativo.

Igualmente, os gestos podem ser categorizados de acordo com o movimento em gesto estático, dinâmico e contínuo. O gesto estático consiste em uma pose especifica que o sistema reconhece como significativa. Um exemplo de gesto estático é o sinal de OK. Porém, deve-se empregar o símbolo com cuidado, visto que possui diferentes interpretações em outras culturas. O gesto dinâmico permite que o usuário manipule diretamente um objeto, do qual recebe um feedback imediato em relação à ação executada. O gesto contínuo não reconhece uma postura específica, mas sim rastreia os movimentos do usuário que são utilizados para interagir com o aplicativo.

Segundo Rogers, Sharp e Preece (2013), uma preocupação central no design da interface natural é determinar a intenção do usuário. O sensor Kinect ${ }^{\circledR}$ visualiza o usuário de uma maneira holística, por isso torna-se difícil compreender a diferença entre um gesto dêitico (um movimento intencional) e um gesto falso positivo (um movimento inconsciente). $O$ falso positivo consiste em um movimento espontâneo que o usuário realiza em um contexto social enquanto gesticula com outras pessoas. Assim, o principal desafio é detectar a diferença dos gestos pretendidos pelo usuário e os falsos positivos.

Os métodos adotados pela plataforma Kinect ${ }^{\circledR}$ com o propósito de determinar a intenção do usuário para interagir com o aplicativo, trata-se de acenar com a mão. O usuário acena pelo menos três vezes em frente ao sensor para que o movimento seja reconhecido como uma intenção para iniciar a interação. O movimento de acenar com a mão é um gesto universal que representa um "olá", ou seja, demonstra que uma pessoa tem a intenção de interagir com outra. 
É importante utilizar um número pequeno de gestos na interface natural, de maneira que o usuário possa aprendê-los e memorizá-los com facilidade. Os usuários conseguem aprender e memorizar no máximo seis gestos, em virtude disso torna-se essencial limitar a carga cognitiva do usuário para não o sobrecarregar com gestos a serem lembrados. Uma das alternativas para reduzir a quantidade de gestos no aplicativo é utilizar a mesma linguagem gestual para as tarefas similares, pois, dessa maneira, os usuários podem inferir os gestos que devem ser empregados.

Existem seis gestos de navegação comuns utilizados no Xbox One ${ }^{\circledR}$ com o Sensor Kinect ${ }^{\circledR}$ (XBOX, 2014). Um dos gestos-guias mais utilizados para interagir com os aplicativos desenvolvidos para o Kinect ${ }^{\circledR}$ é "Fazer uma seleção". Inicialmente, eleva-se a mão com a palma aberta sobre um item ou bloco específico, movimentando-a para frente e depois para trás para fazer a seleção.

Uma maneira eficaz de utilizar os jogos para o Kinect ${ }^{\circledR}$ em situações de treinamento e terapia está relacionada com o feedback "liderar pelo exemplo". O usuário acompanha os movimentos ou uma ação específica do avatar. À medida que o usuário executa os movimentos aparece uma indicação na tela demonstrando se a ação foi realizada com êxito ou não. Um dos melhores exemplos do feedback "liderar pelo exemplo" é o jogo Dance Central Spotlight (HARMONIX, 2014a), do qual o avatar ensina os passos de dança para o usuário que deve copiar os movimentos em tempo real. Quando os movimentos do jogador estão em descompasso com os movimentos do avatar, os membros são destacados em vermelho para indicar que o jogador cometeu um erro.

Outra questão importante que deve ser levada em consideração no design de interação da interface natural são as características do público-alvo. Dado que a obtenção de um gesto correto pode levar a muitos ajustes e iterações, é importante realizar testes de usabilidade frequentes a fim de avaliar toda a gama de usuários pretendidos. Além da diferença de altura e comprimento dos membros, existe a diferença na destreza e controle dos movimentos, o que torna o movimento de uma criança muito distinto do gesto executado por um adulto. Sendo assim, os gestos devem funcionar para todas as faixas de altura, assim como as capacidades físicas e cognitivas dos usuários.

Tendo em vista o que foi apresentado anteriormente, o lançamento do sensor de movimento Kinect ${ }^{\circledR}$ chamou a atenção não apenas da indústria do entretenimento, mas também foi visto como um passo importante para a tecnologia baseada nos gestos naturais (WALKER, 2012). No entanto, a interface natural requer a realização de novos estudos para propiciar melhoramentos em vários aspectos, especialmente em relação à acessibilidade da interface, com a finalidade de proporcionar experiências de uso eficazes independente da habilidade do usuário. 


\section{METODOLOGIA}

A presente pesquisa trata-se de um estudo de caso utilizando uma abordagem qualitativa. Foi realizada uma intervenção durante oito semanas com três idosos frequentadores do projeto de extensão Celari, vinculado à ESEF da UFRGS.

O projeto atende pessoas com mais de 55 anos, oferecendo diversas atividades que estimulam a prática de atividade física e a interação social. As atividades físicas disponibilizadas para o idoso são: hidroginástica, jogging aquático, natação, ginástica localizada, equilíbrio e dança. Além disso, o projeto Celari oportuniza outras ações que motivam a socialização entre os participantes como saraus literários no intuito de propiciar a qualidade de vida e o bem-estar das pessoas idosas.

A seleção do grupo abrangeu homens e mulheres considerados caidores, ou seja, que apresentam fator preditivo para o risco de quedas com idade igual ou superior a 60 anos frequentadores do projeto de extensão Celari, residentes na cidade de Porto Alegre - RS e região metropolitana.

Os instrumentos de coleta de dados utilizados na pesquisa foram a observação direta e o questionário. Foram elaborados dois questionários com questões fechadas: o primeiro foi aplicado antes da intervenção para identificar o perfil dos usuários. Houve a aplicação de um secundo questionário após a intervenção auxiliar na identificação dos requisitos de projeto.

Em relação aos instrumentos de intervenção, foi utilizado o console Xbox One ${ }^{\circledR}$ com o Kinect $2.0^{\circledR}$ e sete jogos digitais. Os dispositivos foram conectados a uma televisão digital de 32 polegadas. Os jogos selecionados para a intervenção com o grupo focal foram: Dance Central Spotlight (HARMONIX, 2014a), Just Dance 2015 (UBISOFT, 2014a), Kinect Sports Rivals (RARE, 2014), Shape Up (UBISOFT, 2014b), Fantasia: Music Evolved (HARMONIX, 2014b), Zumba Fitness: World Party (ZOË MODE, 2013) e Boom Ball for Kinect (VIRTUAL AIR GUITAR COMPANY, 2014).

Os procedimentos para a realização da pesquisa podem ser acompanhados a seguir:

1o Estratégia de divulgação: foram elaborados cartazes e "mosquetinhos" para divulgar a pesquisa, sendo fixados no mural do Celari juntamente com a lista de inscrição para que os interessados em participar da pesquisa pudessem se inscrever. A pesquisadora percorreu algumas salas de aula e convidou as pessoas com mais de 60 anos e com propensão às quedas a participar da pesquisa. Do mesmo modo, o equipamento (Xbox One ${ }^{\circledR} \mathrm{com}$ Kinect ${ }^{\circledR}$ e televisão) foi instalado na sala de convivência do Celari onde as 
pessoas costumam se encontrar antes das aulas. A divulgação ocorreu durante uma semana no período da manhã e à tarde. As pessoas puderam experimentar os mesmos jogos que seriam aplicados na intervenção, incluindo os jogos de dança, esporte, aventura e treinamento.

2o Seleção dos participantes e distribuição aleatória dos grupos: dez pessoas inscreveram-se para participar da pesquisa. Os participantes foram distribuídos de maneira completamente aleatória em dois grupos com cinco pessoas. Foram realizadas duas sessões semanais, sendo que o primeiro grupo realizou as atividades nas terças-feiras e o segundo grupo nas quintas-feiras. Ao final do período de intervenção três pessoas continuaram participando de forma assídua na pesquisa.

\section{Coleta de dados (pré-teste) e Termo de Consentimento Livre e}

Esclarecido (TCLE): na primeira semana de intervenção, foi solicitado ao grupo que assinasse o TCLE com o intuito de informar e esclarecer às pessoas os riscos e benefícios sobre a sua participação no projeto de pesquisa. Igualmente, foi aplicado o questionário pré-teste para identificar o perfil dos usuários.

4ำ Realização da intervenção: as sessões foram realizadas em um período de oito semanas com frequência de duas sessões semanais e duração de 45 minutos. A intervenção ocorreu no primeiro semestre de 2015, tendo início no dia 19 de maio e término no dia 16 de julho. As sessões aconteceram nas terças e quintas a partir das 16h na sala de ginástica do Centro Natatório da ESEF, no espaço concedido gentilmente pelo Celari.

5o Coleta de dados (pós-teste) e análise dos dados: no final da intervenção, foi aplicado o questionário pós-intervenção com a intenção de obter informações na perspectiva dos idosos, com vistas a auxiliar no processo de desenvolvimento dos requisitos de projeto. Foi feita uma análise qualitativa da informação obtida através da observação direta e dos questionários aplicados pré e pós-intervenção.

\section{RESULTADOS E ANÁLISE DOS RESULTADOS}

Para alcançar o objetivo proposto com a presente pesquisa, foi aplicado o Desdobramento da Função Qualidade (em inglês, Quality Function Deployment - QFD), do qual permite converter os requisitos dos usuários em requisitos de projeto utilizando a matriz de conversão ou de relações do desdobramento da função qualidade. Para Back et al. (2008, p. 227), o propósito do relacionamento entre os requisitos dos usuários e os requisitos técnicos do projeto é a obtenção

$1 \quad$ A pesquisa foi avaliada e aprovada pelo Comitê de Ética em Pesquisa da Universidade Federal do Rio Grande do Sul sob o número 1.083.595. 
de indicativos (valores) de quanto cada necessidade ou desejo do usuário afeta ou é afetado por um parâmetro técnico. Os resultados dos relacionamentos assim obtidos determinam o grau de importância dos requisitos de projeto.

Após a intervenção, foi estabelecido um conjunto de requisitos dos usuários que expressam as necessidades e preferências do grupo de idosos em relação aos jogos digitais que utilizam a interface natural. Os requisitos dos usuários foram colocados na tabela à esquerda da matriz da qualidade, apresentada no Apêndice A. Utilizou-se a escala de Likert para avaliar o grau de importância dos requisitos dos usuários que podem variar de 1 (menos importante) a 5 (mais importante). Esses valores foram estabelecidos tendo como base a observação direta e os questionários aplicados durante a intervenção com o grupo focal. O peso absoluto é indicado pelo grau de importância dos requisitos de usuário em uma escala de 1 a 5 . O peso relativo (\%) é obtido ao dividir o peso absoluto de cada requisito de usuário pela soma do peso absoluto de todos os requisitos dos usuários.

Posteriormente, os requisitos técnicos do projeto foram dispostos nas colunas acima da matriz da qualidade. Os mesmos foram definidos a partir da revisão de literatura e agrupados em categorias e subcategorias com o intuito de contemplar todas as áreas do desenvolvimento de um jogo digital. Os requisitos técnicos do projeto foram divididos nas categorias de arte (subdividida em gráfico e som), design (interface, gameplay e história) e design técnico (exigências de tecnologia). As células foram preenchidas utilizando códigos de correlação entre os requisitos de usuário e requisitos técnicos do projeto. A correlação entre os requisitos adotada nesta pesquisa foi: 9 para uma relação forte; 5 para uma relação moderada; 1 para uma relação fraca; 0 para uma relação nula.

Segundo Back et al. (2008, p. 227), a tarefa de relacionar os desejos dos usuários com os atributos técnicos é fortemente dependente da experiência e dos conhecimentos dos integrantes da equipe de desenvolvimento. Conforme os autores, se não houver consistência nos relacionamentos realizados, as decisões tomadas poderão comprometer as demais tarefas do QFD e qualidade das soluções obtidas para o problema (BACK et al., 2008, p. 228). Nesse sentido, formou-se uma equipe composta por três especialistas com experiência em desenvolvimento de jogos digitais para a verificação do QFD.

Em uma etapa posterior, foi calculado o peso absoluto e o peso relativo (\%) dos requisitos de projeto. O valor do peso absoluto é obtido ao multiplicar o grau de importância do requisito dos usuários pelos valores numéricos das correlações e somar estes produtos verticalmente (CHENG; MELO, 2010). O peso relativo (\%) é calculado ao dividir o peso absoluto de cada requisito técnico de projeto pela soma do peso absoluto de todos os atributos técnicos. Esses valores definem o grau de importância dos requisitos de projeto. 
Além disso, o método QFD possibilita correlacionar os requisitos técnicos do projeto. A análise é realizada através do "telhado" da casa da qualidade cujo propósito é auxiliar na relação de compromissos entre os requisitos e verificar quais serão as implicações quando algum atributo do produto for alterado (BACK et al., 2008). Dessa maneira, a equipe de desenvolvimento pôde identificar as relações de conflito no projeto e buscar soluções para os problemas encontrados. Em geral, recomenda-se dar prioridade ao requisito com peso maior quando se identifica uma relação de conflito.

\subsection{Requisitos de Projeto}

Com base nos resultados obtidos nas etapas referentes à priorização dos requisitos de projeto e análise do relacionamento entre os requisitos técnicos do projeto, elaborou-se um quadro (Quadro 1) com os objetivos e restrições dos requisitos. Os requisitos de projeto foram sistematizados por ordem de importância, sendo o feedback o requisito com o maior peso e o fluxo com o menor grau de importância.

Quadro 1 - Objetivo e restrições dos requisitos de projeto

\begin{tabular}{|c|c|c|}
\hline $\begin{array}{l}\text { Requisitos de } \\
\text { Projeto }\end{array}$ & Objetivos & Restrições \\
\hline Feedback & $\begin{array}{l}\text { Convém aumentar o feedback } \\
\text { positivo e negativo, especialmente, } \\
\text { em relação aos movimentos do } \\
\text { jogador. }\end{array}$ & $\begin{array}{l}\text { Embora o feedback negativo } \\
\text { possa ser desencorajador para } \\
\text { muitos jogadores, o mesmo pode } \\
\text { auxiliar nos jogos que exigem a } \\
\text { movimentação do corpo, pois, } \\
\text { quando o usuário tem indicações de } \\
\text { que um movimento está incorreto, } \\
\text { ele pode corrigi-lo a fim de melhorar } \\
\text { o seu desempenho. }\end{array}$ \\
\hline Interação gestual & $\begin{array}{l}\text { Convém diminuir a carga de } \\
\text { memória de trabalho, oferecendo } \\
\text { uma quantidade menor de gestos } \\
\text { e movimentos a serem aprendidos } \\
\text { e memorizados, além de adequá- } \\
\text { los às limitações físicas das } \\
\text { pessoas idosas. }\end{array}$ & $\begin{array}{l}\text { O desafio nos jogos com uma } \\
\text { interface baseada nos gestos } \\
\text { e na movimentação do corpo } \\
\text { está, muitas vezes, associado } \\
\text { à dificuldade em executar um } \\
\text { movimento. Ao reduzir a dificuldade } \\
\text { das interações gestuais, é possível } \\
\text { que o jogador perca o interesse pelo } \\
\text { jogo ao longo do tempo. }\end{array}$ \\
\hline Personagens & $\begin{array}{l}\text { Convém diminuir a quantidade } \\
\text { de personagens na tela do jogo } \\
\text { para facilitar a identificação dos } \\
\text { avatares. }\end{array}$ & $\begin{array}{l}\text { É necessário oferecer um recurso } \\
\text { que possa facilitar o reconhecimento } \\
\text { dos avatares no modo multijogador } \\
\text { local. }\end{array}$ \\
\hline $\begin{array}{l}\text { Mecânicas } \\
\text { Adequadas }\end{array}$ & $\begin{array}{l}\text { Convém adequar as mecânicas ao } \\
\text { propósito do jogo, proporcionando } \\
\text { experiências que se aproximem à } \\
\text { atividade de vida diária dos idosos } \\
\text { na intenção de treinar habilidades } \\
\text { que são importantes para esse } \\
\text { público. }\end{array}$ & $\begin{array}{l}\text { Procurar balancear o propósito do } \\
\text { jogo com a diversão. Nesse caso, o } \\
\text { objetivo principal do jogo consiste } \\
\text { em melhorar o equilíbrio, reduzir o } \\
\text { risco de quedas e, em consequência, } \\
\text { melhorar a qualidade de vida da } \\
\text { população idosa. }\end{array}$ \\
\hline
\end{tabular}




\begin{tabular}{|c|c|c|}
\hline $\begin{array}{l}\text { Requisitos de } \\
\text { Projeto }\end{array}$ & Objetivos & Restrições \\
\hline $\begin{array}{l}\text { Curva de } \\
\text { aprendizagem }\end{array}$ & $\begin{array}{l}\text { Convém suavizar a curva de } \\
\text { aprendizagem, oferecendo tempo } \\
\text { suficiente para que um jogador } \\
\text { inexperiente possa aprender o } \\
\text { jogo. }\end{array}$ & $\begin{array}{l}\text { Na medida em que os jogadores } \\
\text { ganham experiência, torna-se } \\
\text { conveniente inserir, gradativamente, } \\
\text { novos obstáculos para manter o } \\
\text { jogador interessado no jogo. }\end{array}$ \\
\hline Diversão & $\begin{array}{l}\text { Convém aumentar a diversão do } \\
\text { jogo para idosos, incluindo os } \\
\text { componentes que podem tornar a } \\
\text { experiência de jogo interessante } \\
\text { e divertida, especialmente no que } \\
\text { se refere ao gosto subjetivo da } \\
\text { audiência. Sendo assim, sugere-se } \\
\text { utilizar elementos que possam } \\
\text { agradar os idosos quanto aos } \\
\text { gráficos, sons e narrativa. }\end{array}$ & $\begin{array}{l}\text { É importante equilibrar os desafios } \\
\text { que tornam a experiência divertida } \\
\text { com o propósito principal do jogo, } \\
\text { considerando, igualmente, as } \\
\text { limitações físicas e cognitivas das } \\
\text { pessoas idosas. }\end{array}$ \\
\hline Sistema de HUD & $\begin{array}{l}\text { Convém diminuir a quantidade } \\
\text { de painéis do sistema de HUD } \\
\text { para evitar excesso de informação } \\
\text { visual na tela do jogo. }\end{array}$ & $\begin{array}{l}\text { A redução dos painéis do sistema de } \\
\text { HUD na área ativa do jogo não deve } \\
\text { afetar o requisito de feedback. }\end{array}$ \\
\hline Voz & $\begin{array}{l}\text { Convém aumentar o feedback } \\
\text { positivo, utilizando palavras } \\
\text { positivas como "Isso aí!" e } \\
\text { "Perfeito!", bem como fornecer a } \\
\text { ajuda através da voz. }\end{array}$ & $\begin{array}{l}\text { Deve haver uma coerência entre a } \\
\text { estética musical da voz, a aparência } \\
\text { do jogo e as preferências do público- } \\
\text { alvo. }\end{array}$ \\
\hline $\begin{array}{l}\text { Requisitos do } \\
\text { sistema }\end{array}$ & $\begin{array}{l}\text { Convém desenvolver o jogo para } \\
\text { a plataforma PC com o sensor de } \\
\text { movimento Kinect }{ }^{\circledR} \text {, utilizando as } \\
\text { ferramentas de desenvolvimento } \\
\text { disponibilizadas pela Microsoft }{ }^{\circledR} \text {. }\end{array}$ & $\begin{array}{l}\text { Os requisitos mínimos do sistema } \\
\text { devem ser compatíveis com os } \mathrm{PCs} \\
\text { utilizados pelo público-alvo. }\end{array}$ \\
\hline $\begin{array}{l}\text { Digitalização do } \\
\text { jogador }\end{array}$ & $\begin{array}{l}\text { Convém utilizar o recurso } \\
\text { de digitalização do jogador, } \\
\text { com vistas a tornar o avatar } \\
\text { semelhante ao jogador, o que, } \\
\text { possivelmente, irá aumentar o } \\
\text { engajamento e a diversão. }\end{array}$ & $\begin{array}{l}\text { O recurso de digitalização dos } \\
\text { jogadores poderá demandar um } \\
\text { tempo maior de aprendizado para } \\
\text { executar os movimentos que } \\
\text { permitem a digitalização do jogador. }\end{array}$ \\
\hline Efeitos sonoros & $\begin{array}{l}\text { Convém aumentar os efeitos } \\
\text { sonoros com a finalidade de } \\
\text { reforçar o feedback sonoro, visto } \\
\text { que os usuários idosos estão mais } \\
\text { atentos aos recursos de áudio dos } \\
\text { jogos. }\end{array}$ & $\begin{array}{l}\text { Assim como no requisito de voz, } \\
\text { é importante adequar à estética } \\
\text { musical dos efeitos sonoros, ao } \\
\text { visual proposto para o jogo e às } \\
\text { exigências do público-alvo. }\end{array}$ \\
\hline Tecnologia & $\begin{array}{l}\text { Convém utilizar o sensor de } \\
\text { movimento Kinect }{ }^{\circledR} \text {, uma vez que } \\
\text { o dispositivo é mais apropriado } \\
\text { para atender aos requisitos } \\
\text { exigidos pelos usuários. }\end{array}$ & $\begin{array}{l}\text { Possibilitar o rastreamento dos } \\
\text { movimentos de todo o corpo e não } \\
\text { apenas das mãos do jogador. }\end{array}$ \\
\hline $\begin{array}{l}\text { Tempo para a } \\
\text { ação }\end{array}$ & $\begin{array}{l}\text { Convém aumentar o tempo para } \\
\text { a ação, dado que as mecânicas } \\
\text { baseadas em restrição de tempo } \\
\text { não são adequadas, ou mesmo } \\
\text { interessantes, para o público } \\
\text { idoso. }\end{array}$ & $\begin{array}{l}\text { Se o tempo for um elemento } \\
\text { importante no jogo, deve-se atribuir } \\
50 \% \text { mais tempo para que o jogador } \\
\text { idoso possa concluir a tarefa em } \\
\text { relação a uma pessoa jovem. }\end{array}$ \\
\hline $\begin{array}{l}\text { Elementos do } \\
\text { ambiente }\end{array}$ & $\begin{array}{l}\text { Convém diminuir a quantidades } \\
\text { de elementos no ambiente com } \\
\text { o intuito de evitar excesso de } \\
\text { informação visual na tela do jogo. }\end{array}$ & $\begin{array}{l}\text { O jogo deve apresentar uma } \\
\text { aparência atraente e adequada } \\
\text { às expectativas do público-alvo, } \\
\text { utilizando gráficos estilizados, cores } \\
\text { vibrantes e alto contraste entre os } \\
\text { elementos do ambiente. }\end{array}$ \\
\hline
\end{tabular}




\begin{tabular}{|c|c|c|}
\hline $\begin{array}{l}\text { Requisitos de } \\
\text { Projeto }\end{array}$ & Objetivos & Restrições \\
\hline $\begin{array}{l}\text { Customização } \\
\text { dos personagens }\end{array}$ & $\begin{array}{l}\text { Convém oferecer a possibilidade } \\
\text { de customizar os personagens } \\
\text { para torná-los semelhantes aos } \\
\text { jogadores. }\end{array}$ & $\begin{array}{l}\text { O recurso de customização dos } \\
\text { personagens poderá demandar um } \\
\text { tempo maior de aprendizado para } \\
\text { navegar nas telas que possibilitam } \\
\text { alterar a aparência dos personagens. }\end{array}$ \\
\hline Telas do jogo & $\begin{array}{l}\text { Convém diminuir o número } \\
\text { "cliques" para que o jogador possa } \\
\text { acessar o jogo com facilidade. } \\
\text { Além disso, é aconselhável evitar } \\
\text { as telas compartilhadas no modo } \\
\text { multijogador local. }\end{array}$ & $\begin{array}{l}\text { A diminuição das telas do jogo não } \\
\text { deverá sobrecarregar os painéis do } \\
\text { sistema de HUD. }\end{array}$ \\
\hline Adaptatividade & $\begin{array}{l}\text { Convém incluir o recurso de } \\
\text { adaptatividade, de maneira que } \\
\text { seja possível adequar a dificuldade } \\
\text { do jogo à habilidade do jogador. }\end{array}$ & $\begin{array}{l}\text { Embora a adaptatividade possa } \\
\text { trazer bons resultados em relação } \\
\text { aos jogadores idosos, é um recurso } \\
\text { difícil de ser implementado pela } \\
\text { equipe de produção do jogo. }\end{array}$ \\
\hline $\begin{array}{l}\text { Câmera em } \\
\text { terceira pessoa }\end{array}$ & $\begin{array}{l}\text { Convém utilizar a câmera com a } \\
\text { perspectiva em terceira pessoa } \\
\text { para que o jogador possa ver o seu } \\
\text { avatar na tela do jogo }\end{array}$ & $\begin{array}{l}\text { Na perspectiva em terceira pessoa, } \\
\text { a câmera é posicionada atrás e na } \\
\text { altura do ombro do personagem, } \\
\text { oferecendo uma visão limitada para } \\
\text { o jogador. }\end{array}$ \\
\hline $\begin{array}{l}\text { Cenas de corte } \\
\text { (cut-scenes) }\end{array}$ & $\begin{array}{l}\text { Convém disponibilizar cenas de } \\
\text { corte (cut-scenes) para introduzir } \\
\text { novos ambientes e personagens, } \\
\text { além de trazer maiores detalhes } \\
\text { sobre a narrativa. }\end{array}$ & $\begin{array}{l}\text { Evitar que as cenas de corte (cut- } \\
\text { scenes) prejudiquem o estado de } \\
\text { fluxo do jogador. }\end{array}$ \\
\hline Dificuldade de IA & $\begin{array}{l}\text { Convém diminuir a dificuldade dos } \\
\text { oponentes nos jogos em que há } \\
\text { competição contra os personagens } \\
\text { de IA. }\end{array}$ & $\begin{array}{l}\text { Deve-se balancear a dificuldade } \\
\text { do jogo, inserindo novos desafios à } \\
\text { medida que o jogador progride, pois } \\
\text { um jogo muito fácil pode entediar os } \\
\text { jogadores idosos. }\end{array}$ \\
\hline $\begin{array}{l}\text { Visualização do } \\
\text { status }\end{array}$ & $\begin{array}{l}\text { Convém melhorar a visualização } \\
\text { do status do jogador, considerando } \\
\text { as limitações decorrentes do } \\
\text { declínio da função visual em } \\
\text { idosos, de forma que os jogadores } \\
\text { possam acompanhar o seu } \\
\text { desempenho no jogo. }\end{array}$ & $\begin{array}{l}\text { Não é aconselhável apresentar } \\
\text { uma tela de visualização do status } \\
\text { complexa, no qual os jogadores } \\
\text { casuais e menos experientes } \\
\text { possam ter dificuldade em } \\
\text { compreender as informações } \\
\text { relativas ao status do jogador. }\end{array}$ \\
\hline $\begin{array}{l}\text { Gênero } \\
\text { adequado ao } \\
\text { público }\end{array}$ & $\begin{array}{l}\text { Convém utilizar os gêneros dança, } \\
\text { esporte, aventura e treinamento, } \\
\text { pois possibilitam a prática } \\
\text { de atividade física e são mais } \\
\text { adequados às preferências das } \\
\text { pessoas idosas. }\end{array}$ & $\begin{array}{l}\text { Evitar que haja um esforço } \\
\text { físico excessivo para realizar os } \\
\text { movimentos que esses gêneros de } \\
\text { jogos exigem. }\end{array}$ \\
\hline Avatarização & $\begin{array}{l}\text { Convém utilizar a avatarização, } \\
\text { recurso no qual o sensor realiza a } \\
\text { captura de movimento do jogador } \\
\text { e representa na tela de jogo por } \\
\text { meio de um avatar. }\end{array}$ & $\begin{array}{l}\text { O recurso de avatarização poderá } \\
\text { ficar comprometido pela utilização } \\
\text { da câmera em terceira pessoa, uma } \\
\text { vez que essa perspectiva oferece } \\
\text { uma visão limitada do avatar. }\end{array}$ \\
\hline $\begin{array}{l}\text { Adequação da } \\
\text { música temática }\end{array}$ & $\begin{array}{l}\text { Convém adequar a trilha sonora } \\
\text { do jogo segundo as preferências } \\
\text { das pessoas idosas, o que inclui } \\
\text { as músicas que eles estavam } \\
\text { acostumados a ouvir na juventude. }\end{array}$ & $\begin{array}{l}\text { Buscar uma coerência entre a trilha } \\
\text { sonora, a aparência geral do jogo e } \\
\text { as preferências do público-alvo. }\end{array}$ \\
\hline
\end{tabular}




\begin{tabular}{|c|c|c|}
\hline $\begin{array}{l}\text { Requisitos de } \\
\text { Projeto }\end{array}$ & Objetivos & Restrições \\
\hline Cooperação & $\begin{array}{l}\text { Convém incluir a cooperação } \\
\text { nos jogos para idosos, pois } \\
\text { as mecânicas que envolvem } \\
\text { a colaboração e o trabalho } \\
\text { em equipe podem aumentar } \\
\text { o engajamento, facilitar a } \\
\text { aprendizagem e estimular a } \\
\text { interação social. }\end{array}$ & $\begin{array}{l}\text { Deve-se ter em mente que o } \\
\text { recurso de cooperação deve } \\
\text { ser implementado no modo } \\
\text { multijogador local. }\end{array}$ \\
\hline $\begin{array}{l}\text { Recompensas } \\
\text { significativas }\end{array}$ & $\begin{array}{l}\text { Convém oferecer recompensas } \\
\text { significativas para os jogadores } \\
\text { idosos a fim de enfatizar um } \\
\text { sentimento de vitória. }\end{array}$ & $\begin{array}{l}\text { Evitar que os efeitos de celebração } \\
\text { das recompensas atrapalhem o } \\
\text { gameplay. }\end{array}$ \\
\hline $\begin{array}{l}\text { Adequação da } \\
\text { narrativa }\end{array}$ & $\begin{array}{l}\text { Convém adequar a narrativa às } \\
\text { preferências do público-alvo. }\end{array}$ & $\begin{array}{l}\text { Deve-se considerar que a atenção } \\
\text { dos jogos que possuem uma } \\
\text { interface baseada nos gestos e na } \\
\text { movimentação do corpo está mais } \\
\text { voltada para a habilidade física do } \\
\text { que para uma narrativa complexa. }\end{array}$ \\
\hline $\begin{array}{l}\text { Esforço de } \\
\text { compreensão } \\
\text { das metas }\end{array}$ & $\begin{array}{l}\text { Convém diminuir o esforço de } \\
\text { compreensão das metas no intuito } \\
\text { tornar o gameplay mais fácil } \\
\text { para um público casual e menos } \\
\text { experiente. }\end{array}$ & $\begin{array}{l}\text { A redução dos painéis do sistema de } \\
\text { HUD não deve afetar a visualização } \\
\text { das metas alcançadas e a serem } \\
\text { cumpridas pelo jogador. }\end{array}$ \\
\hline $\begin{array}{l}\text { Esforço de } \\
\text { compreensão } \\
\text { das regras }\end{array}$ & $\begin{array}{l}\text { Convém diminuir o esforço de } \\
\text { compreensão das regras. }\end{array}$ & $\begin{array}{l}\text { A diminuição dos painéis de HUD } \\
\text { não deve influenciar as informações } \\
\text { que auxiliam o entendimento das } \\
\text { regras do jogo. }\end{array}$ \\
\hline Modo de jogador & $\begin{array}{l}\text { Convém oferecer o modo } \\
\text { multijogador local, dado que a } \\
\text { interação social proporcionada } \\
\text { pelo jogo é um elemento } \\
\text { importante nos jogos para os } \\
\text { idosos, conforme também foi } \\
\text { relatado na literatura. }\end{array}$ & $\begin{array}{l}\text { Deve-se ter em vista as limitações } \\
\text { do sensor Kinect }{ }^{\circledR} \text { que consegue } \\
\text { rastrear até seis pessoas } \\
\text { simultaneamente. }\end{array}$ \\
\hline Fluxo & $\begin{array}{l}\text { Convém balancear a dificuldade } \\
\text { do jogo com a habilidade do } \\
\text { jogador para mantê-lo envolvido } \\
\text { com a experiência de jogo. }\end{array}$ & $\begin{array}{l}\text { Deve-se oferecer o tempo } \\
\text { adequado para que os jogadores } \\
\text { idosos possam conquistar novas } \\
\text { habilidades. }\end{array}$ \\
\hline
\end{tabular}

\section{CONSIDERAC̣õES FINAIS}

Com significativas alterações demográficas ocorridas nas últimas décadas, o aumento da população senescente no Brasil, que era uma consequência já esperada, se torna realidade. Essa questão passa a exigir, então, um olhar mais atento, tanto das políticas públicas, quanto do setor privado, na intenção de assegurar que as pessoas com mais de 60 anos possam viver com autonomia e independência, por meio de iniciativas que visam contribuir para um envelhecimento saudável.

De acordo com UNFPA (2012), existe uma demanda para o desenvolvimento e uso de tecnologias inovadoras que promovam o envelhecimento ativo. Isso é, especialmente, importante quando as pessoas 
envelhecem e vivenciam a diminuição da mobilidade, da capacidade visual e auditiva. Produtos que propiciam um envelhecimento ativo são essenciais para assegurar a autonomia, independência, qualidade de vida e expectativa de vida saudável da população de idosos.

Durante a pesquisa, ficou evidente a falta de interesse em se desenvolver produtos interativos que levem em consideração as limitações decorrentes do processo de envelhecimento que podem atingir as funções motoras, cognitivas e sensoriais. Sendo assim, a pesquisa oferece um conjunto priorizado de requisitos que podem, eventualmente, orientar uma equipe de artistas, designers e programadores no desenvolvimento de um jogo digital com um propósito específico.

Conforme os resultados apresentados, espera-se que o conhecimento gerado com essa pesquisa possa beneficiar os profissionais da indústria dos jogos digitais, ou mesmo os pesquisadores do meio acadêmico, que tenham interesse em desenvolver um jogo sério, com vistas a melhorar a qualidade de vida dos usuários idosos por meio dos jogos digitais que utilizam a interface natural.

\section{AGRADECIMENTOS}

Os pesquisadores agradecem ao projeto de extensão Celari, vinculado à ESEF da UFRGS, por possibilitar a realização dessa pesquisa.

\section{REFERÊNCIAS}

BACK, Nelson; OGLIARI, André; DIAS, Acires; SILVA, Jonny Carlos. Projeto integrado de produtos: planejamento, concepção e modelagem. Barueri: Manole, 2008.

CAMARANO, Ana Amélia; KANSO, Solange. Envelhecimento da população brasileira: uma contribuição demográfica. In: FREITAS, Elizabete Viana; PY, Ligia; CANÇADO, Flávio Aluizio Xavier; DOLL, Johannes; GORZONI, Milton Luiz. Tratado de geriatria e gerontologia. 3. ed. Rio de Janeiro: Guanabara Koogan, 2011. p. 133-152.

CHENG, Lin Chih; MELO, Leonel Del Rey De. QFD: desdobramento da função qualidade na gestão de desenvolvimento de produtos. 2. ed. São Paulo: Blücher, 2010. 
PILLON, Carolina Bravo; SILVA, Régio Pierre da; ALMEIDA, Carla Skilhan de

HARMONIX. Fantasia: music evolved. Cambridge: Harmonix Disponível em: <http:// goo.gl/7LTSpS>. Acesso em: 1 jul. 2014b.

IBGE. Instituto Brasileiro de Geografia e Estatística. Síntese de indicadores sociais: uma análise das condições de vida da população brasileira. Rio de Janeiro: IBGE, 2010.

IESS. Instituto de Estudos de Saúde Suplementar. Envelhecimento populacional e os desafios para o sistema de saúde brasileiro. São Paulo: IESS, 2013.

MAILLOT, Pauline; PERROT, Alexandra; HARTLEY, Alan. Effects of interactive physicalactivity video-game training on physical and cognitive function in older adults. Psychology and Aging, Washington, v. 27, n. 3, p. 589-600, set. 2012.

MARINELLI, Elena C.; ROGERS, Wendy A. Identifying potential usability challenges for xbox 360 kinect exergames for older adults. Proceedings of the Human Factors and Ergonomics Society Annual Meeting, [S. I.], v. 58, n. 1, p. 1247-1251, set. 2014.

MCLAUGHLIN, Anne; GANDY, Maribeth; ALLAIRE, Jason; WHITLOCK, Laura. Putting fun into video games for older adults. Ergonomics in Design: the quarterly of human factors applications, Springs, v. 20, n. 2, p. 13-22, abr. 2012.

MICHAEL, David; CHEN, Sande. Serious games: games that educate, train, and inform. Mason: Thomson Course Technology, 2006.

MICROSOFT. Kinect for windows: human interface guidelines v 1.8. [S.I.]: Microsoft Corporation, 2013.

OMS. Organização Mundial da Saúde. Envelhecimento ativo: uma política de saúde. Brasília: Organização Pan-Americana da Saúde, 2005.

RARE. Kinect sports rivals. Twycross: Rare, 2014. Disponível em: <http://goo.gl/ bpB8Bx>. Acesso em: 16 out. 2014.

ROGERS, Scott. Level UP: um guia para o design de grandes jogos. São Paulo: Edgar Blucher, 2012.

ROGERS, Yvonne; SHARP, Helen; PREECE, Jennifer. Design de interação: além da interação humano-computador. 3. ed. Porto Alegre: Bookman, 2013.

SALEN, Katie; ZIMMERMAN, Eric. Regras do jogo: fundamentos do design de jogos. São Paulo: Edgard Blucher, 2012. v. 1.

SCHUYTEMA, Paul. Design de games: uma abordagem prática. São Paulo: Cengage Learning, 2008. 
TREML, Cleiton José; KALIL FILHO, Faruk Abrão; CICCARINO, Renata Franco Leite; WEGNER, Rosemari Sandra; SAITA, Cleide Yoko de Souza; CORRÊA, Aline Geronasso. $O$ uso da plataforma balance board como recurso fisioterápico em idosos. Revista Brasileira de Geriatria e Gerontologia, Rio de Janeiro, v. 16, n. 4, p. 759-768, dez. 2013.

UBISOFT. Just dance 2015. Montreuil: Ubisoft, 2014a. Disponível em: <http://goo.gl/ vsPgP>. Acesso em: 16 out. 2014.

UBISOFT. Shape up. Montreal: Ubisoft, 2014b. Disponível em: <http://goo.gl/ dLbGTT>. Acesso em: 16 out. 2014.

UNFPA. Fundo de População das Nações Unidas. Envelhecimento no século XXI: celebração e desafio. New York: UNFPA, 2012.

UNITED NATIONS. World population ageing 2013. Nova York: United Nations, 2013.

VIRTUAL AIR GUITAR COMPANY. Boom ball for kinect. Helsinki: Virtual Air Guitar Company, 2014. Disponível em: <http://goo.gl/wUB8Hm>. Acesso em: 1 jul. 2014.

WALKER, Rob. How kinect spawned a commercial ecosystem. The New York Times, 31 maio 2012. Disponível em: <http://goo.gl/FnZyl>. Acesso em: 5 set. 2014.

WI, Sam Yeol; KANG, Jong Ho; JANG, Jun Hyeok. Clinical feasibility of exercise game for depression treatment in older women with osteoarthritis: a pilot study. Journal of Physical Therapy Science, Saitama, v. 25, n. 2, p. 165-167, 2013.

WIBELINGER, Lia Mara; BATISTA, Juliana Secchini; VIDMAR, Marlon Francys; KAYSER, Bárbara; PASQUALOTTI, Adriano; SCHNEIDER, Rodolfo Herberto. Efeitos da fisioterapia convencional e da wiiterapia na dor e capacidade funcional de mulheres idosas com osteoartrite de joelho. Revista Dor, São Paulo, v. 14, n. 3, p. 196-199, jul./ set. 2013.

WIGDOR, Daniel; WIXON, Dennis. Brave NUI world. Boston: Morgan Kaufmann, 2011.

XBOX. Gestos de navegação comuns do Kinect no Xbox One. Disponível em: <http:// goo.gl/qHuO5s>. Acesso em: 6 set. 2014.

ZOË MODE. Zumba fitness: world party. Brighton: Zoë Mode, 2013. Disponível em: <http://goo.gl/gH4xKR>. Acesso em: 1 jul. 2014. 
PILLON, Carolina Bravo; SILVA, Régio Pierre da; ALMEIDA, Carla Skilhan de

Apêndice A - Diagrama do Desdobramento da Função Qualidade (QFD).

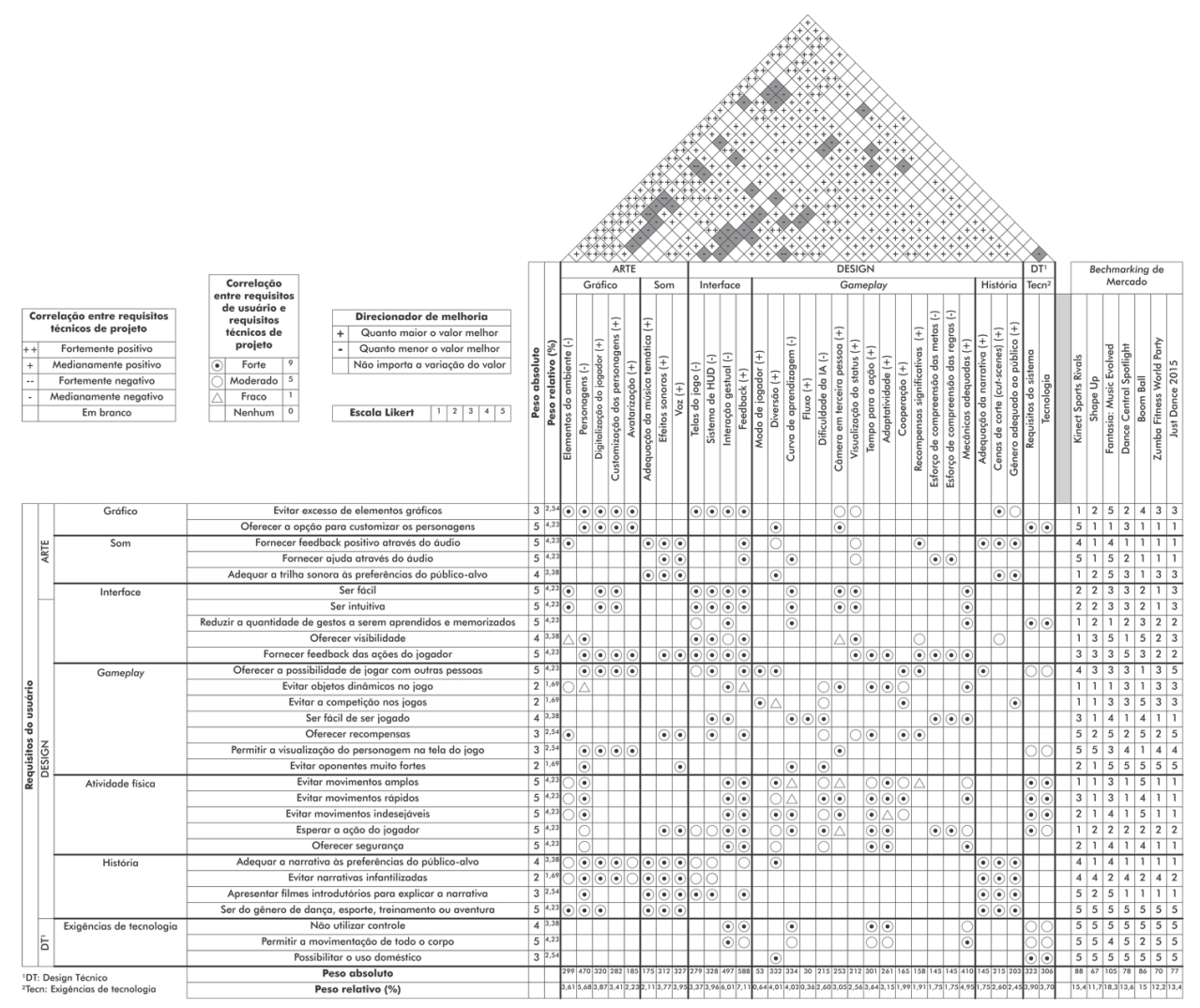

Projética, Londrina, v.9, n.1, p. 105-122, Jan./Jun. 2018 